\title{
Solidification of Hypereutectic Thin Wall Ductile Cast Iron
}

\section{Pedersen, Karl Martin; Tiedje, Niels Skat}

Published in:

Solidification and Gravity IV Material Science Forum

Publication date:

2006

Link back to DTU Orbit

Citation (APA):

Pedersen, K. M., \& Tiedje, N. S. (2006). Solidification of Hypereutectic Thin Wall Ductile Cast Iron. In Solidification and Gravity IV Material Science Forum (Vol. 508, pp. 63-68). Trans Tech Publications Ltd.. Materials Science Forum Vol. 508

\section{General rights}

Copyright and moral rights for the publications made accessible in the public portal are retained by the authors and/or other copyright owners and it is a condition of accessing publications that users recognise and abide by the legal requirements associated with these rights.

- Users may download and print one copy of any publication from the public portal for the purpose of private study or research.

- You may not further distribute the material or use it for any profit-making activity or commercial gain

- You may freely distribute the URL identifying the publication in the public portal

If you believe that this document breaches copyright please contact us providing details, and we will remove access to the work immediately and investigate your claim 


\title{
Solidification of Hypereutectic Thin Wall Ductile Cast Iron
}

\author{
Karl Martin Pedersen ${ }^{1, a}$ and Niels Tiedje ${ }^{1, b}$ \\ ${ }^{1}$ Department of Manufacturing Engineering and Management, Technical University of Denmark, \\ Building 425, DK-2800 Kgs. Lyngby, Denmark \\ akmp@ipl.dtu.dk, ${ }^{\mathrm{a}} \mathrm{nt} @ i p l . d t u . d k$
}

Keywords: Ductile cast iron, solidification, thin wall, microstructure, nucleation, kinetic.

\begin{abstract}
Hypereutectic ductile iron was cast in green sand moulds with four plates with thickness of 1.5, 2, 3 and $4 \mathrm{~mm}$ in each mould. Temperatures were measured in the 3 and $4 \mathrm{~mm}$ plate. The temperature curves showed that eutectic solidification was divided into two stages: primary and secondary eutectic solidification. The first stage, which was relatively short, had none or very little recalescence. Further under cooling, followed by reheating during recalescence, was necessary to initiate the second part of the eutectic solidification. Both the secondary under cooling and recalescence was larger in the $3 \mathrm{~mm}$ plates than in the $4 \mathrm{~mm}$ plates. All $1.5 \mathrm{~mm}$ plates contained carbides but the other plates solidified without carbides. Metallographic examination showed two populations of graphite nodules. A small group of nodules was larger than rest of the nodules. Colour etching revealing the segregation of Si showed a higher Si content in the ferrite around the larger nodules compared to the ferrite around the rest of the nodules. This indicates that solidification took place along the following path: The solidification starts with nucleation and growth of primary graphite nodules. This probably starts during the filling of the mould. The primary nodules act as nuclei for austenite. As austenite easily nucleates on graphite the temperature will be the same for the 3 and $4 \mathrm{~mm}$ plate for the first part of the eutectic solidification. This first part of the solidification ends when concentration of carbon around austenite dendrites is too large and new nodules have to nucleate and grow. The larger under cooling for the $3 \mathrm{~mm}$ plates compared to the $4 \mathrm{~mm}$ indicates that the nucleation of new nodules is governed by kinetics even in very well inoculated melts.
\end{abstract}

\section{Introduction}

The need to save weight in the automotive industry calls for development of lighter constructions. This can be achieved either by using lighter materials or by optimizing existing constructions so that they become lighter e.g. by reducing the wall thickness or removing superfluous material.

Ductile cast iron has been used successfully for decades for safety parts in cars, trucks etc. The material has good mechanical properties: strength, ductility, fatigue strength etc. Traditionally ductile iron constructions have been relatively heavy, but for many applications it is possible to reduce wall thickness and still have sufficient strength in the material to suit the purpose. When the wall thickness of a casting is reduced, the cooling rate in the casting is increased causing the conditions for phase transformations to be changed. In very thin walled ductile iron castings (less than $4 \mathrm{~mm}$ ) solidification conditions are different to what is normally encountered in ductile iron. Therefore the conditions for nucleation and growth of phases during solidification are changed too.

In the present investigation we will investigate the solidification conditions in very thin walled ductile iron castings in order to describe conditions for phase formation and growth kinetics.

\section{Experimental procedure}

Ductile cast iron was produced in batches of $100 \mathrm{~kg}$. Composition of charge materials is listed in Table 1 and the chemical analysis of the castings are in Table 2. The melt was superheated to $1520^{\circ} \mathrm{C}$ before being poured into a preheated ladle for magnesium treatment using a tundish sandwich method. From the treatment ladle the melt was poured into a small insulated fiber cup 
where it was inoculated with $0,4 \%$ inoculant. The melt was then poured into a pouring basin with a stopper placed on the top of the moulds. When the pouring basin was full the stopper was removed after 7 seconds. The temperature was measured in the pouring basin by using S-type thermocouple. The temperature was about $1325^{\circ} \mathrm{C}$ in the pouring basin. The moulds were made of greensand on a DISAmatic 2110 Moulding Machine. Four moulds were used for the casting, see Table 3. Four plates with thickness of 1,5, 2, 3 and $4 \mathrm{~mm}$ were cast in each mould, see Fig. 1 . The temperature was measured in the 3 and $4 \mathrm{~mm}$ plate with K-element thermocouple of 0,2 $\mathrm{mm}$ wire. The thermocouples were prefabricated and mounted in a core. The cores were placed during the production of moulds. The sample rate for temperature measurement was $500 \mathrm{~Hz}$ and every 50 values were averaged to reduce noise giving a time increment of 0,1 second. In mould 3 a copper chill was placed in order to get a chilled sample, $3 \mathrm{~mm}$ thick, for metallographic examination and chemical analysis.

The characterization of graphite morphology and matrix microstructure was performed on a cross section of the plate close to the thermocouple (the same height as the core on Fig. 1). Graphite morphology was characterized by using image analysis. The two dimensional spatial size distribution of nodules was converted to a three dimensional size distribution by Schwarts-Saltykov Analysis [1]. Nodules below $5 \mu \mathrm{m}$ were rejected in the counts. The samples were etched in a 3\% nital solution to reveal ferrite, pearlite and carbides.

To reveal segregation of Si a colour etching, Klemm I, was used [2]. The etching time was about 2 minutes. In the ferritic regions around the nodules the low silicon zones will have a blue colour while high silicon zones will have a pale colour.

Table 1 Composition of charge materials

\begin{tabular}{|l|l|}
\hline Material & Composition \\
\hline DI pig iron & $1,10 \% \mathrm{Si}, 3,94 \% \mathrm{C}, 0,018 \% \mathrm{Mn}, 0,017 \% \mathrm{P}, 0,005 \% \mathrm{~S}, \mathrm{Bal} \mathrm{Fe}$ \\
\hline Ferrosilicon & $56,7 \% \mathrm{Si}, 0,84 \% \mathrm{Al}, \mathrm{Bal} \mathrm{Fe}$ \\
\hline Mg-treatment & $44,8 \% \mathrm{Si}, 3,2 \% \mathrm{Mg}, 0,37 \% \mathrm{Ca}, 2,16 \% \mathrm{RE}, 0,67 \% \mathrm{Al}, \mathrm{Bal} \mathrm{Fe}$ \\
\hline Inoculant A & $74,9 \% \mathrm{Si}, 3,59 \% \mathrm{Al}, 1,2 \% \mathrm{Ca}, \mathrm{Bal} \mathrm{Fe}$ \\
\hline Inoculant B & $73,0 \% \mathrm{Si}, 0,94 \% \mathrm{Ca}, 1,9 \% \mathrm{Ce}, 0,95 \% \mathrm{Al}$, trace of S and O, Bal Fe \\
\hline
\end{tabular}

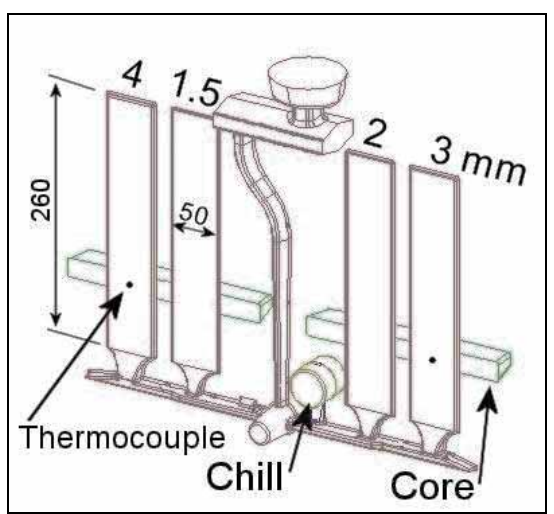

Fig. 1 Casting layout with core and copper chill
Table 2 Chemical analysis of the castings ( $\mathrm{CE}=\mathrm{C}+0,28 * \mathrm{Si})$

\begin{tabular}{|c|c|c|c|c|c|c|c|}
\hline Mould & C & Si & Mn & P & S & Mg & CE \\
\hline $1+4$ & 3,7 & 3,05 & 0,05 & 0,020 & 0,009 & 0,028 & 4,55 \\
\hline $2+3$ & 3,7 & 3,35 & 0,05 & 0,020 & 0,009 & 0,028 & 4,64 \\
\hline
\end{tabular}

Table 3 Overview over the experiement

\begin{tabular}{|c|c|c|c|}
\hline Mould & Inoculant & Chill & $\begin{array}{c}\text { Time after Mg- } \\
\text { treatment }\end{array}$ \\
\hline 1 & None & & $2: 00$ \\
\hline 2 & A & & $2: 20$ \\
\hline 3 & B & Yes & $2: 35$ \\
\hline 4 & None & & $4: 30$ \\
\hline
\end{tabular}

\section{Results}

Cooling Curves. An example of a cooling curve can be seen in Fig. 2 together with a curve showing the cooling rate $(\mathrm{dT} / \mathrm{dt})$. In the figure some characteristic temperatures are indicated. T12 is defined as the first maximum of the dT/dt curve and T21 is defined as the local minimum of the $\mathrm{dT} / \mathrm{dt}$ curve. T23 is the minimum and T31 is the maximum temperature during the secondary eutectic solidification. A close up of the eutectic solidification for mould 1 and 2 can be seen in Fig. 3. On the close up the time scale has been modified for the $3 \mathrm{~mm}$ plate to make it easier to compare 
the solidification of the 3 and $4 \mathrm{~mm}$ plate. There seems to be two eutectic arrests, a primary with a maximum growth rate at temperature T12 and a secondary starting at temperature T21. The solidification slows down for $1 / 2-1$ seconds, before the second part of eutectic solidification starts. For the first part of the solidification the temperature difference between the 3 and $4 \mathrm{~mm}$ plate are small, but for the second part of the solidification the local minimum temperature T23 will be lower for $3 \mathrm{~mm}$ plate compared to the $4 \mathrm{~mm}$ plate. This can be illustrated by the temperature difference T12-T23. The differences are about $2^{\circ} \mathrm{C}$ larger for $3 \mathrm{~mm}$ plate than for $4 \mathrm{~mm}$, see Table 4 . A paired $\mathrm{t}$-Test gives a significant difference with a p-value of 0,017 .

The temperature recalescence $\mathrm{T}_{\text {rec }}$ (T31-T23) is about $1^{\circ} \mathrm{C}$ larger in $3 \mathrm{~mm}$ plates compared to 4 mm plates. A paired t-Test gives a p-value of 0,04 .

The under cooling is $10-15^{\circ} \mathrm{C}$ larger for the uninoculated moulds compared to the inoculated, but the larger under cooling also gives a large recalescence.

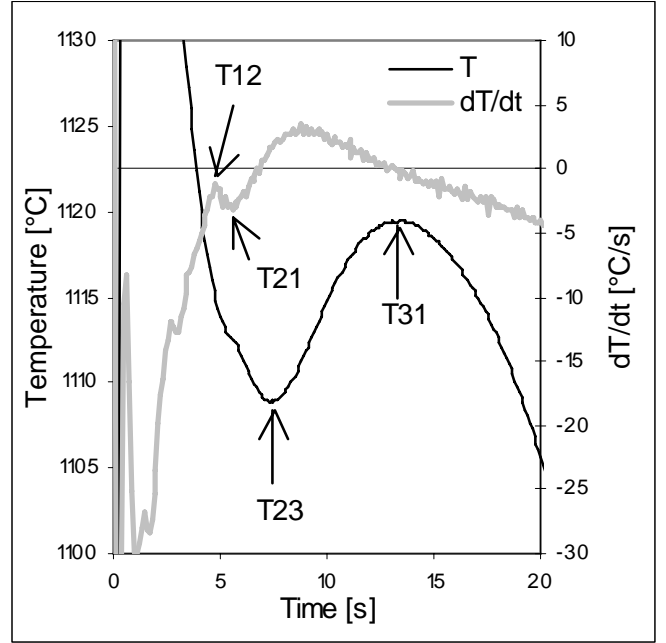

Fig. 2 Definition of temperatures
Table 4 The main temperatures

\begin{tabular}{|c|c|c|c|c|c|}
\hline & Mould & 1 & 4 & 2 & 3 \\
\hline & & \multicolumn{2}{|c|}{ Not inoculated } & \multicolumn{2}{|c|}{ inoculated } \\
\hline \multirow{2}{*}{ T12 } & $4 \mathrm{~mm}$ & 1112,3 & 1109,1 & 1121,1 & 1120,8 \\
\hline & $3 \mathrm{~mm}$ & 1112,6 & 1109,2 & 1120,4 & 1122,3 \\
\hline \multirow{2}{*}{$\mathrm{T} 21$} & $4 \mathrm{~mm}$ & 1110,7 & 1107,9 & 1122,1 & 1121,6 \\
\hline & $3 \mathrm{~mm}$ & 1110,7 & 1107,0 & 1119,7 & 1121,8 \\
\hline \multirow{2}{*}{$\mathrm{T} 23$} & $4 \mathrm{~mm}$ & 1108,9 & 11107,5 & $\overline{11122,0}$ & 11121,2 \\
\hline & $3 \mathrm{~mm}$ & 1107,4 & 1103,8 & 1119,5 & 1120,7 \\
\hline \multirow{2}{*}{ T31 } & $4 \mathrm{~mm}$ & 1119,4 & 1118,7 & 1124,7 & 1123,8 \\
\hline & $3 \mathrm{~mm}$ & 1119,8 & 1116,0 & 1122,6 & 1124,3 \\
\hline \multirow{2}{*}{ T12-T23 } & $4 \mathrm{~mm}$ & 3,4 & 1,6 & $-0,9$ & $-0,4$ \\
\hline & $3 \mathrm{~mm}$ & 5,2 & 5,4 & 0,9 & 1,6 \\
\hline \multirow{2}{*}{$\begin{array}{c}\mathrm{T}_{\text {rec }} \\
\mathrm{T} 31-\mathrm{T} 23\end{array}$} & $4 \mathrm{~mm}$ & 10,4 & 11,2 & 2,7 & 2,6 \\
\hline & $3 \mathrm{~mm}$ & 12,4 & 12,2 & 3,1 & 3,6 \\
\hline
\end{tabular}

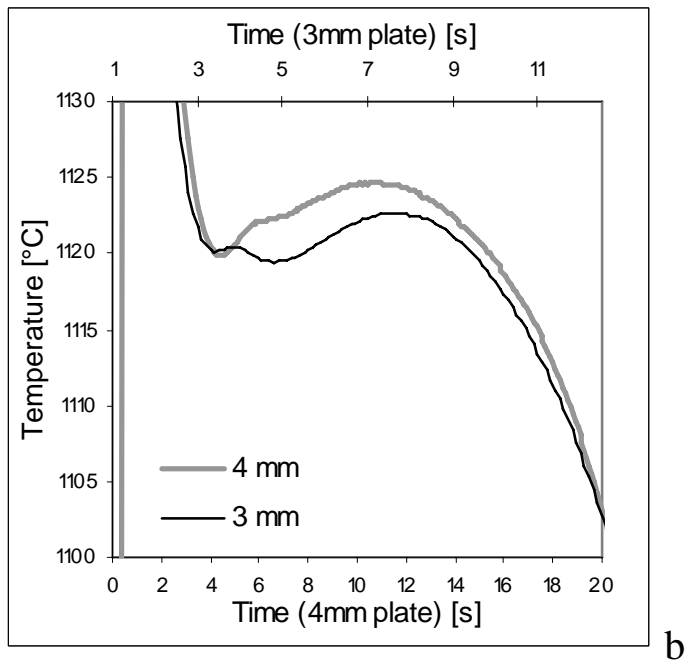

Fig. 3 Cooling curves. a) Not inoculated (mould 1), and b) inoculated (mould 2)

Microstructure. Examples of microstructures can be seen on Fig. 5. The number of nodules pr volume and the average nodule size can be seen in Fig. 4. As the plate thickness decrease the number of nodules increase and the average nodule size decrease. The inoculated castings have higher nodule counts and smaller nodule size than the uninoculated castings. Most of the nodules 
are concentrated around the average nodule size, but a group of nodules of about 500-2000 nodules $/ \mathrm{mm}^{3}$ have a size, which is larger than the main group of nodules. This can also be seen on a sample from the top of the $1,5 \mathrm{~mm}$ plate (Fig. $6 \mathrm{a}+\mathrm{b}$ ).

All $1.5 \mathrm{~mm}$ plates contain carbides, but the rest of the plates have solidified without carbides, even in the mould 1 and 4 that not were inoculated. The tendency to shrinkage was higher in the inoculated moulds (mould 2 and 3) compared to mould 1 and 4 . This indicates the use of $0.4 \%$ inoculant will give a melt that is over inoculated and that the nucleation potential of the melt has been very high.

On colour-etched samples the ferrite around the larger nodules in general has a paler colour than the ferrite around the smaller nodules (see Fig. 6d). At the nital etched sample from the top of the 1,5 $\mathrm{mm}$ plate a pearlite shell surrounds the large nodules while there are carbides close to the small nodules (see Fig. 6b)
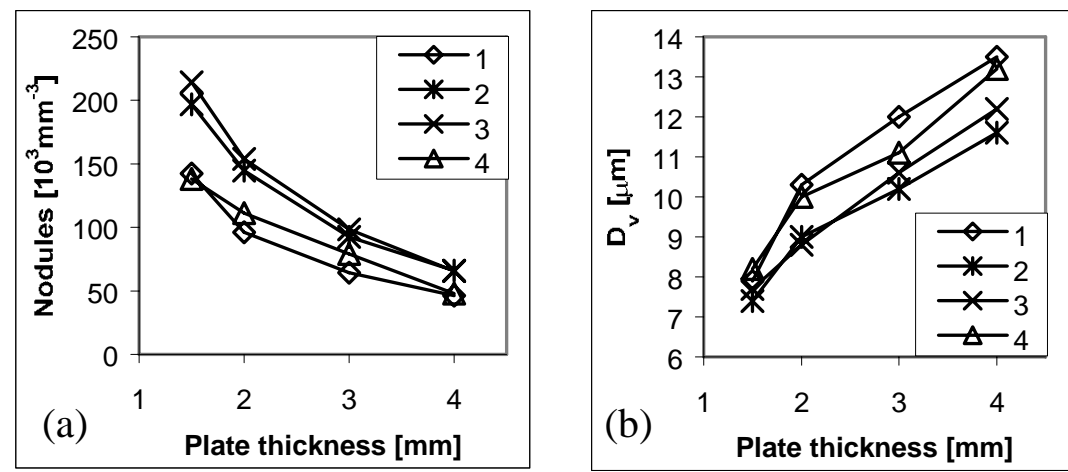

Fig. 4 (a): Nodules pr. Volume. (b): Average nodule size
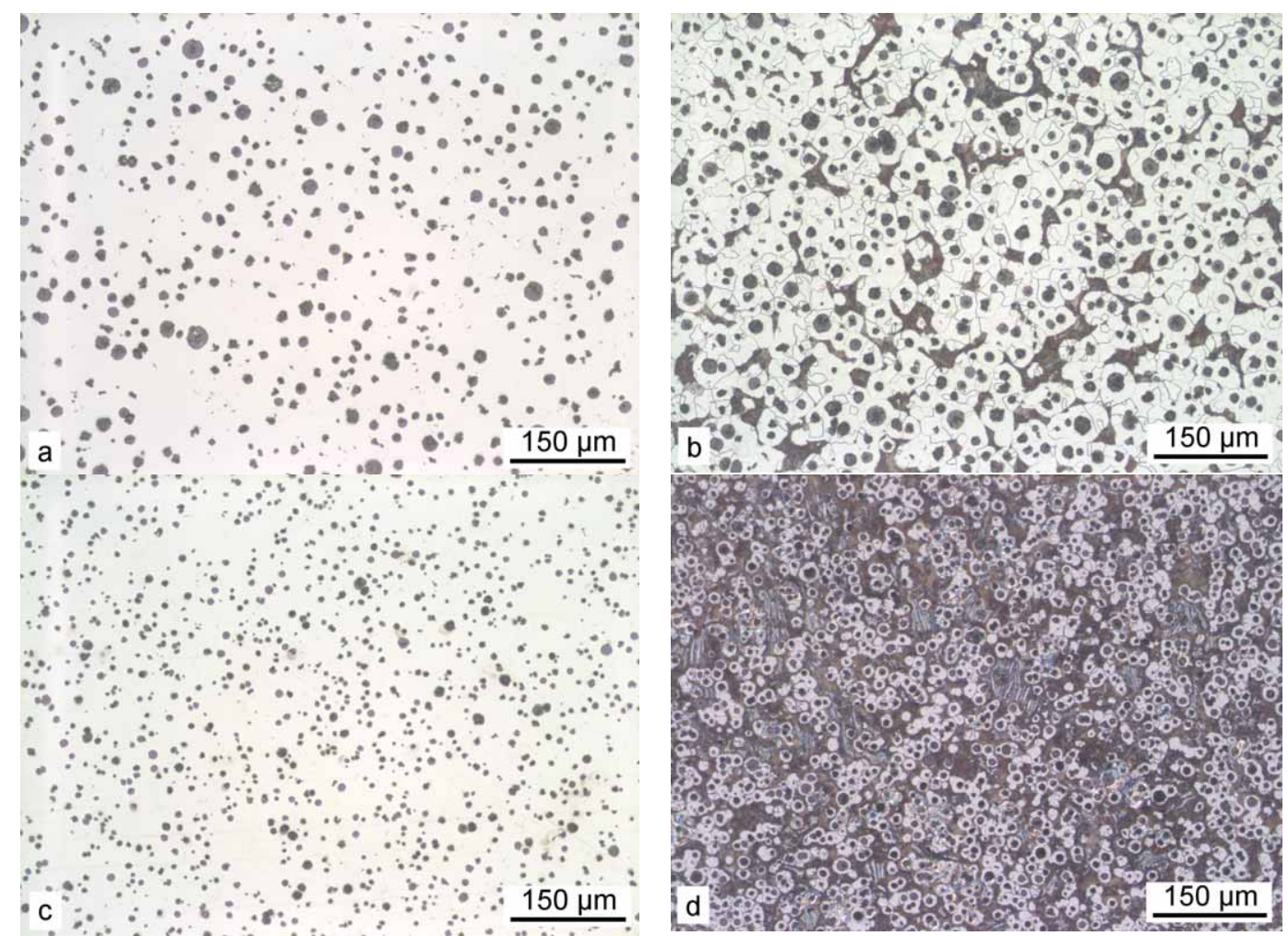

Fig. 5 Mould 3: 4 mm plate unetch (a) and etch (b); $1.5 \mathrm{~mm}$ plate unetch (c) and etch (d) 


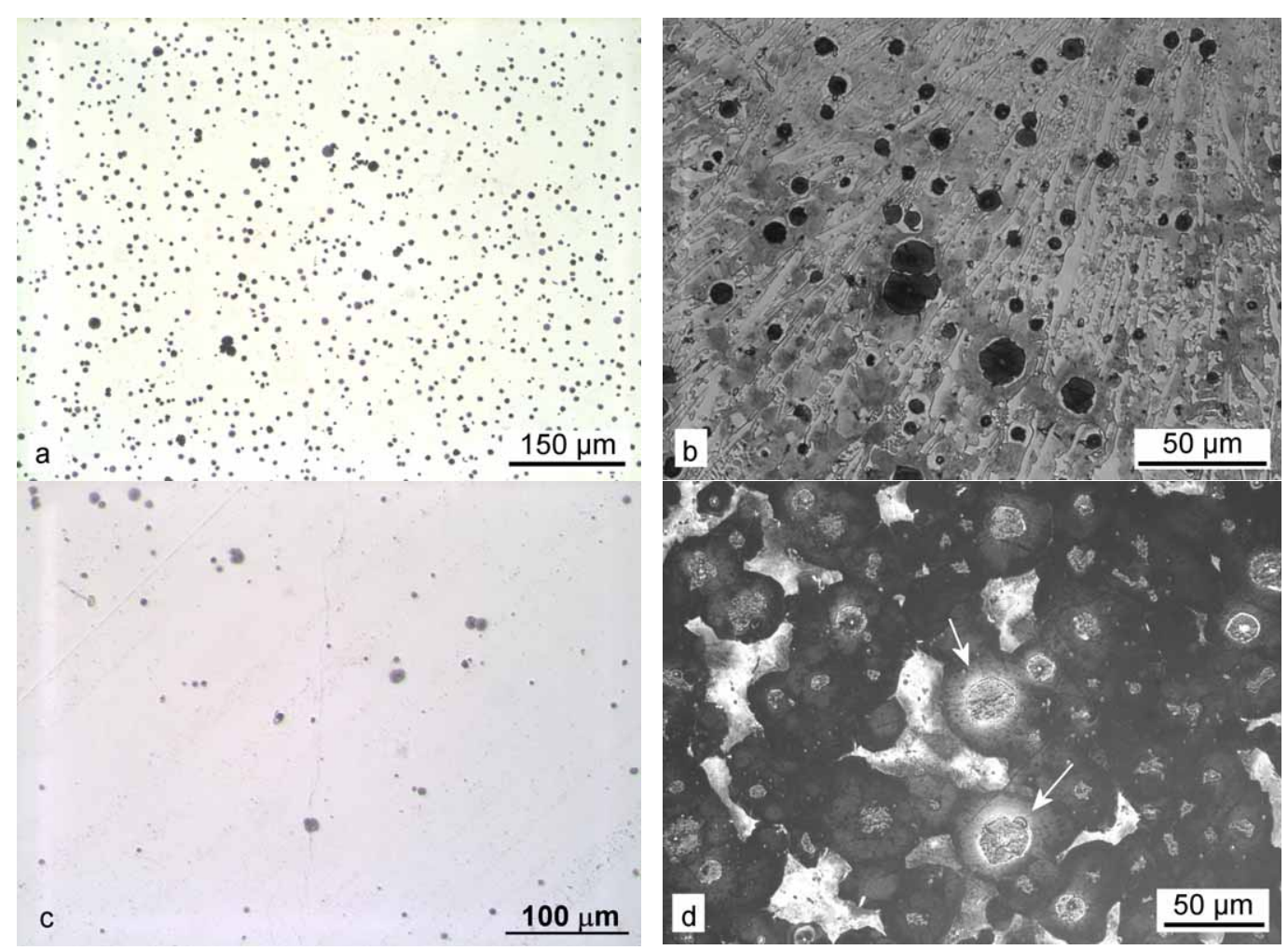

Fig. 6 Mould 3, top of 1,5mm plate, unetch (a), nital etch (b). Chilled sample (c). $4 \mathrm{~mm}$ plate, colour etched, high Si-content are marked with arrows (d)

\section{Discussion}

The melts were hypereutectic and by that it is expected that graphite will be nucleated as the first phase during solidification. The graphite-liquid temperature TGL can be calculated by [3]:

$$
\text { TGL }=389 *(\% \mathrm{C}+0,29 * \% \mathrm{Si})-534,5^{\circ} \mathrm{C} .
$$

This gives a TGL of $1249^{\circ} \mathrm{C}$ for the uninoculated and $1283^{\circ} \mathrm{C}$ for the inoculated moulds. This is below the casting temperature of $1325^{\circ} \mathrm{C}$, but the nucleation of graphite has probably started during filling of the mould, as the maximum measured temperatures in the plates are about $1200^{\circ} \mathrm{C}$. This also explains the presence of graphite nodules in the chilled samples (see Fig. 6c).

The first arrest at temperature T12 can be explained by the nucleation and growth of graphite. But according to Heine et.al. the heat evolution from graphite precipitation is small and changes in slope rather than arrests are usually obtained [4]. Here the arrest at T12 is very clear, especially in the inoculated moulds, showing a large heat evolution and this indicates the presence of eutectic solidification at this temperature.

The presence of a few larger nodules indicates, that these nodules have been nucleated in the beginning of the solidification and have had longer time to grow than the rest of the nodules. At the colour-etched samples the ferritic shells around these larger nodules have a higher content of Si. At a nital etched sample from the top of the $1.5 \mathrm{~mm}$ plate, in general only the larger nodules have a shell of pearlite (Fig. 6b). This indicates that the first part of the eutectic solidification consisted of these larger nodules surrounded by austenite.

Looking at the colour etched samples it is important to remember that the used colour etching reagent only is reliable in the ferritic area and not in the pearlite. It has been shown that the solidification structure of austenite in ductile iron will be dendritic (e.g. [5-7]). According to Loper graphite can act as an effective nucleant for austenite [8]. As soon as the temperature is below the eutectic temperature austenite will start to nucleate and grow on the primary graphite nodules. The austenite will probably rapidly envelope the primary nodules because of the low carbon content around the nodule. The growth of the austenite will generate sufficient heat enough to be visible on 
the cooling curve at the temperature T12. As austenite nucleates easily the difference in cooling rate between the 3 and $4 \mathrm{~mm}$ plates will only have very little influence on this process. Here cooling rate will control solidification rather than kinetics.

As the austenite grows there will be an increase in carbon content around the austenite, which will slow down the growth rate of the austenite. New nodules have to be nucleated. In this stage the under cooling becomes larger for $3 \mathrm{~mm}$ plates. This indicates that the nucleation of new nodules is governed by kinetics.

The solidification morphology of this casting can be described as following: 1: Nucleation and growth of primary graphite nodules, probably started during filling of the mould. 2: Nucleation and growth of austenite dendrite. During growth of the dendrite carbon will be rejected to the melt around the dendrites. 3: Nucleation of graphite nodules in the area around the dendrites with high concentration of carbon. 4: Growth of austenite and graphite to the end of solidification.

\section{Conclusions}

Castings of hypereutectic thin wall ductile have been performed with temperature measurement in 3 and $4 \mathrm{~mm}$ plates. The temperature measurements revealed that the eutectic solidification could be divided into a primary and secondary eutectic solidification.

The examination of the microstructure revealed some nodules, which were larger than the main group of nodules. The Si-content in the ferrite around the larger nodules was higher compared to the ferrite around other nodules. The larger nodules have probably been nucleated in the beginning of the solidification and have acted as nuclei for austenite. The under cooling for this part of the solidification was the same for the 3 and $4 \mathrm{~mm}$ plates.

Later in the solidification new nodules have to be nucleated. This is governed by kinetics and there was a larger under cooling in the $3 \mathrm{~mm}$ plates compared to $4 \mathrm{~mm}$ for this part of the solidification.

\section{References}

[1] E. E. Underwood, Quantitative Stereology (Addison-Wesley Publishing Company, 1970).

[2] E. Weck and E. Leistner, Metallographic instructions for colour etching by immersion (Deutsher Verlag für Schweisstechnik (DVS) GmbH, Düsseldorf 1982).

[3] J. Lacaze, M. Castro and G. Lesoult: Acta Materialia Vol. 46 (1998), p. 997.

[4] R. W. Heine, C. R. Jr. Loper and M. O. Chaudhari: AFS Transactions Vol. 79 (1971), p. 399.

[5] R. Boeri and F. Weinberg: AFS Transactions Vol. 97 (1989), p. 179.

[6] G. Rivera, R. Boeri and J. Sikora: Materials Science and Technology Vol. 18 (2002), p. 691.

[7] C. F. Yeung, H. Zhao and W. B. Lee: Materials Characterization Vol. 40 (1998), p. 201.

[8] C. R. Jr. Loper: AFS Transactions Vol. 107 (1999), p. 523. 